\title{
Retro-Orbital Neoplasm
}

National Cancer Institute

\section{Source}

National Cancer Institute. Retro-Orbital Neoplasm. NCI Thesaurus. Code C8597.

A benign or malignant neoplasm that affects the retro-orbital region. 